\title{
Desenvolvimento das culturas de cereais de inverno no Rio Grande do Sul por meio de perfis temporais do índice de vegetação por diferença normalizada
}

\author{
Winter cereal crop development in Rio Grande do Sul, Brazil, throughout the temporal profiles of \\ normalized difference vegetation index
}

\author{
Amanda Heemann Junges $^{{ }^{*}}$ Denise Cybis Fontana ${ }^{\mathrm{I}}$
}

\section{RESUMO}

Os objetivos deste trabalho foram elaborar perfis temporais de NDVI/MODIS, mediante a construção de máscaras de cultivo, verificando as variações interanuais dos perfis associadas à variação do rendimento de grãos de trigo no Rio Grande do Sul. Foram utilizadas imagens MOD13 dos meses de maio a novembro para os anos 2000 a 2006, pontos de controle na superfície (coletados em lavouras de trigo, aveia e cevada) e dados oficiais de rendimento médio de grãos de trigo (IBGE e Cotrijal). Os resultados mostraram que, por meio da metodologia de construção de máscaras de cultivo, é possível gerar perfis temporais de NDVI que permitem monitorar o desenvolvimento das lavouras de cereais de inverno e que podem ser empregados no estudo das variações interanuais de rendimento de grãos de trigo. Os maiores rendimentos de grãos estão relacionados à manutenção de altos valores de NDVI (acima de 0,7) por um período maior de tempo. Porém, a metodologia não permitiu a distinção de lavouras de trigo, aveia e cevada, sendo necessários estudos subseqüentes.

Palavras-chave: máscara de cultivos, trigo, aveia, cevada, sensor MODIS.

\section{ABSTRACT}

This research aimed to elaborate temporal NDVI profiles through the crop masks building, and find the interannual variations of profiles associated with variation of wheat grain yield in Rio Grande do Sul, Brazil. The data set were composed by MODIS13 images (NDVI product from May to November, 2000 to 2006), ground control points (collected in wheat, oat and barley fields) and official wheat grain yield (IBGE and Cotrijal). The results showed that using the proposed methodology for crop masking it is possible to generate consistent NDVI temporal profiles, which allows monitoring the development of winter cereal crops and can be used to evaluate the interannual variations of grain yield. The profiles showed that wheat grain yield was related to the maintenance of high NDVI values (above 0.7) for a larger period of time. However, the methodology did not allow the wheat, oats and barley discrimination, pointing for subsequent studies.

Key words: crops mask, wheat, oat, barley, MODIS sensor.

\section{INTRODUÇÃO}

O monitoramento de cultivos agrícolas e as estimativas de safras promovem a regulamentação do comércio, a estabilização de preços e a seguridade alimentar. A metodologia oficial de previsão de safras no Brasil é baseada em questionários aplicados a produtores ou entidades relacionadas à atividade agrícola, o que envolve tempo e custos elevados, além de apresentar alto grau de subjetividade. Tal subjetividade pode ser minimizada pelo uso de tecnologias de sensoriamento remoto, de sistemas de informações geográficas e de modelos agrometeorológicos-espectrais (DEPPE et al., 2007).

Para tanto, é necessário, primeiramente, estabelecer relações entre os parâmetros radiométricos contidos em produtos de sensoriamento remoto e os parâmetros biofísicos da vegetação, o que tem sido feito, com freqüência, por meio de índices de vegetação (EPIPHANIO et al., 1996). O índice de vegetação mais utilizado é o Índice de Vegetação por Diferença Normalizada (NDVI, do inglês Normalized Difference Vegetation Index $)$, dado por: $\mathrm{NDVI}=\left(\mathrm{R}_{\mathrm{IVP}}-\mathrm{R}_{\mathrm{V}}\right) /$

IDepartamento de Plantas Forrageiras e Agrometeorologia, Faculdade de Agronomia, Universidade Federal do Rio Grande do Sul (UFRGS). Av. Bento Gonçalves, 7712, 91540-000, Porto Alegre, RS, Brasil. E-mail: amandahj@hotmail.com.*Autor para correspondência. 
$\left(\mathrm{R}_{\mathrm{IVP}}+\mathrm{R}_{\mathrm{V}}\right)$, sendo $\mathrm{R}_{\mathrm{IVP}}$ e $\mathrm{R}_{\mathrm{V}}$ os fatores de reflectância bidirecional nas regiões do infravermelho próximo e vermelho, respectivamente. Para a cultura do trigo, HAMADA (2000) demonstrou a existência de relação entre NDVI e alguns parâmetros biofísicos (massa fresca total, massas fresca e seca de folhas verdes e índice de área foliar), sendo as maiores correlações encontradas nos estádios de emborrachamento, início do espigamento e maturação. De acordo com RUDORFF \& BATISTA(1990), a integração do NDVI representa a intensidade e a duração da atividade fotossintética das plantas ao longo de seu ciclo de desenvolvimento, estando correlacionada ao rendimento final de grãos.

Perfis temporais de NDVI são obtidos a partir de observações seqüenciais desse índice, logo, mostram o crescimento e desenvolvimento das plantas ao longo dos estádios fenológicos. Quando provenientes de imagens de satélites de baixa resolução espacial e alta resolução temporal, os perfis têm sido propostos em análises regionais de culturas agrícolas, tais como arroz irrigado no Rio Grande do Sul (KLERING, 2007) e cereais de inverno no Paraná (DEPPE et al., 2007) e na Austrália (FONTANA e al., 2007). De acordo com DEPPE et al. (2007), a utilização de imagens de NDVI permite o monitoramento do desenvolvimento fenológico das culturas ao longo das safras, sendo possível obter, assim, avaliações qualitativas e quantitativas dos plantios em períodos anteriores à colheita.

Os objetivos deste trabalho foram elaborar perfis temporais de NDVI/MODIS, mediante a construção de máscaras de cultivo, e verificar as variações interanuais dos perfis associadas à variação do rendimento de grãos de trigo no Rio Grande do Sul.

\section{MATERIAL E MÉTODOS}

A área de estudo, de 394.000 hectares, compreendeu 13 municípios localizados ao Norte do Rio Grande do Sul, principal região produtora de trigo no Estado, pertencentes à área de atuação da Cooperativa Tritícola Mista Alto Jacuí Ltda - Cotrijal.

As imagens do sensor orbital MODIS foram obtidas do banco de imagens do Projeto Geosafras, junto ao Centro Estadual de Pesquisa em Sensoriamento Remoto e Meteorologia da Universidade Federal do Rio Grande do Sul (CEPSRMUFRGS). As imagens utilizadas foram as do produto MOD13, nas quais os valores dos píxeis correspondem a valores de NDVI. As imagens são disponibilizadas na forma de composições de 16 dias, as quais não apresentam cobertura de nuvens. Para cada ponto da imagem, o algoritmo seleciona o píxel de melhor qualidade em relação à geometria de visada e interferência atmosférica, dentre todas as passagens do período. O píxel selecionado é, então, utilizado na geração das imagens compostas. As composições estão disponíveis no website http://www.modis.gsfc.nasa.gov, sem qualquer ônus ao usuário final (RIZZI, 2004).

As imagens NDVI/MODIS empregadas foram referentes ao período que abrange o ciclo da cultura de trigo na área de estudo, ou seja, de maio a novembro, para os anos de 2000 a 2006.

Em 2006 foi realizado um trabalho de campo para coleta de pontos de controle, mediante uso de um equipamento GPS (Global Positioning System), em lavouras cereais de inverno da região. O objetivo foi a localização espacial dessas lavouras nas imagens MODIS. Do posicionamento espacial desses pontos, transferidos para as imagens, foram extraídos valores de NDVI e, a partir destes, confeccionados perfis temporais. Os perfis temporais das lavouras foram utilizados para uma análise inicial da dinâmica temporal dos valores de NDVI característica dos cereais de inverno, trigo, aveia e cevada na região da Cotrijal.

Posteriormente, ampliando a abrangência das análises, as imagens NDVI/MODIS foram empregadas na construção de perfis temporais por meio de duas abordagens: regional e máscara de cultivo. $\mathrm{Na}$ análise regional, os perfis foram elaborados com o NDVI médio de toda área de estudo, ao longo do período de maio a novembro. Nessa primeira abordagem, os perfis temporais resultantes continham informações do índice de vegetação referentes a diferentes alvos, tais como: corpos d'água, centros urbanos, matas, lavouras de cereais de inverno e campos.

Na segunda abordagem, foi proposta a análise utilizando uma máscara de cultivo, de acordo com metodologia proposta por FONTANA et al. (2007). A máscara de cultivo tem como objetivo restringir as informações espectrais. Nesse sentido, o perfil temporal de NDVI foi traçado somente com dados correspondentes a áreas de cultivo. Para construção da máscara de cultivo, foram elaboradas, para cada ano de estudo, imagens de máximo e de mínimo NDVI. Com base nas imagens de máximo NDVI de cada ano, obtevese a imagem de máximo valor de NDVI histórico, na qual cada píxel possui o máximo valor de NDVI dentre as imagens de máximo valor dos anos 2000 a 2006. Posteriormente, foram construídas, para cada ano, as imagens de diferença, que corresponderam à subtração das seguintes imagens: NDVI máximo histórico e NDVI mínimo do ano.

As composições de máximo NDVI foram elaboradas com as imagens dos meses de junho a setembro, período no qual ocorreram, nos diferentes 
anos, os maiores valores de NDVI. As composições de mínimo foram elaboradas com as imagens de abril e de maio, quando as lavouras de inverno estão em implantação ou no início do desenvolvimento vegetativo, visto que o período indicado para semeadura de trigo é de 21 de maio a 30 de junho para a maioria dos 13 municípios pertencentes à região de estudo (REUNIÃO, 2006). A imagem de diferença visou identificar as áreas nas quais ocorreram as maiores variações temporais do NDVI, pois essas áreas correspondem, possivelmente, a lavouras de cereais de inverno. Nas imagens de diferença foram testados limiares para elaboração da máscara de cultivo. O critério de escolha do limiar foi a geração da máscara de cultivo com área igual ou superior à área com cereais de inverno, de acordo com dados oficiais.

As diferenças interanuais nos perfis temporais de NDVI, obtidos com aplicação da máscara de cultivos, foram relacionadas ao rendimento de grãos de trigo, cultura que ocupa a maior área plantada na região de estudo. Os dados de rendimento médio de trigo, para as safras agrícolas de 2000 a 2005, foram provenientes do Levantamento Sistemático da Produção Agrícola (IBGE, 2007). Os valores referentes à safra 2006 foram obtidos junto aos técnicos da Cotrijal, visto que, no momento da realização das análises, o dado do IBGE ainda não estava disponível.

\section{RESULTADOS E DISCUSSÃO}

Os primeiros resultados referem-se aos perfis temporais de NDVI obtidos a partir de pontos coletados nas lavouras de cereais de inverno (trigo, aveia e cevada), da região da Cotrijal, para o ano de 2006. Nessas lavouras, os valores mínimos (próximos a 0,4) e máximos (próximos a 0,8) ocorreram, respectivamente, em abril (período anterior à semeadura) e na primeira quinzena de julho (estádio de desenvolvimento vegetativo) (Figura 1). O NDVI atingiu valor máximo ainda em fase vegetativa, indicando rápido desenvolvimento inicial e acúmulo de biomassa nesse ano. Estudo de EPIPHANIO et al. (1996), que relacionou o comportamento do NDVI ao longo do desenvolvimento da planta de trigo, mostrou que os valores do índice são próximos de 0,5 no início do ciclo e crescentes até atingirem um máximo e se estabilizarem em torno de 0,8 a 0,9. Essa estabilização, que pode ser entendida como o máximo acúmulo de biomassa na parte aérea, ocorre já a partir do alongamento do colmo. Com a maturação fisiológica, os valores voltam a decrescer em função da senescência foliar e da translocação de nutrientes para o grão. Nas lavouras da Cotrijal, em 2006, o decréscimo dos valores de NDVI se deu no início de setembro, ou seja, antes das plantas atingirem a maturação. Isso foi

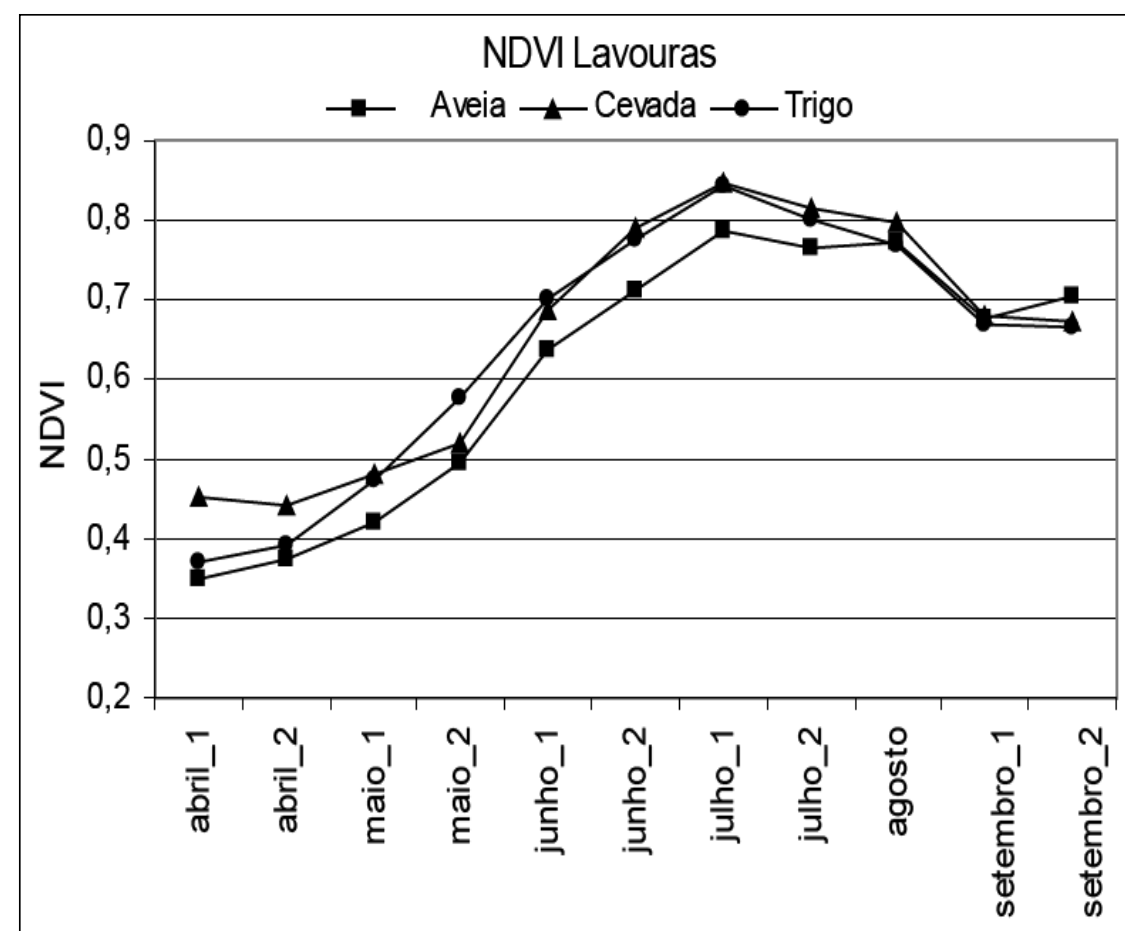

Figura 1 - Perfis temporais de NDVI obtidos em pontos de referência sobre lavouras de aveia, cevada e trigo. Região de abrangência da Cotrijal, 2006.

Ciência Rural, v.39, n.5, ago, 2009. 
conseqüência das baixas temperaturas e geadas ocorridas na região, as quais comprometeram o desenvolvimento das plantas e o rendimento final de grãos.

Coerente ao que foi observado por MOREIRA et al. (2005), devido as semelhanças morfológicas, os perfis de NDVI das lavouras de trigo, aveia e cevada foram semelhantes no que se refere aos valores e à evolução temporal do índice de vegetação. Sendo assim, nas análises posteriores, as culturas agrícolas foram analisadas conjuntamente, sob a denominação de cereais de inverno. Apesar da não distinção, os perfis temporais das lavouras caracterizaram adequadamente o ciclo das culturas agrícolas, contribuindo para uma melhor compreensão do processo de crescimento e desenvolvimento dos cereais de inverno na região de estudo. Além disso, os perfis de NDVI, mostraram-se adequados à identificação da ocorrência de geadas, o que também foi verificado por RAFAELLI et al. (2006) nas regiões cafeeiras no Noroeste do Paraná em julho de 2000.

Os resultados seguintes referem-se à metodologia de máscara de cultivo. As imagens de mínimo e de máximo NDVI, para o ano de 2003, bem como a imagem de diferença, para o referido ano, podem ser visualizadas na figura 2A, 2B e 2C, respectivamente, como forma de demonstração da metodologia. Nas imagens de mínimo, os valores de NDVI situaram-se entre 0,25 e 0,65 (tons amarelados e alaranjados), associados à baixa densidade de biomassa nesse período. Observa-se, no entanto, que ocorreram áreas com valores de NDVI acima de 0,65 (tons esverdeados), as quais corresponderam, provavelmente, às áreas de mata ou às áreas agrícolas (lavouras de verão ainda não colhidas, lavouras de inverno já implementadas ou lavouras estabelecidas com espécies de cobertura). Nas imagens de máximo NDVI, os valores foram acima de 0,65 , indicando o desenvolvimento da vegetação. Nas imagens de máximo, as áreas urbanas, com baixos valores de NDVI, foram salientadas.

Essa metodologia permitiu a inserção, na máscara de cultivo, apenas das áreas da imagem que sofreram as maiores modificações ao longo do período (abril a novembro). Essas áreas correspondem, provavelmente, a lavouras de cereais de inverno, tendo em vista que as áreas estimadas pela máscara de cultivo foram semelhantes às oficiais (IBGE) (Tabela 1). Sendo assim, foram excluídas da máscara as áreas que praticamente não sofreram alterações no período (áreas urbanas ou de mata) ou áreas onde as variações de NDVI ocorreram, mas foram menores do que a verificada nas lavouras (como, por exemplo, campos nativos). Além disso, a metodologia é de baixo custo, em virtude de as imagens MODIS serem disponibilizadas

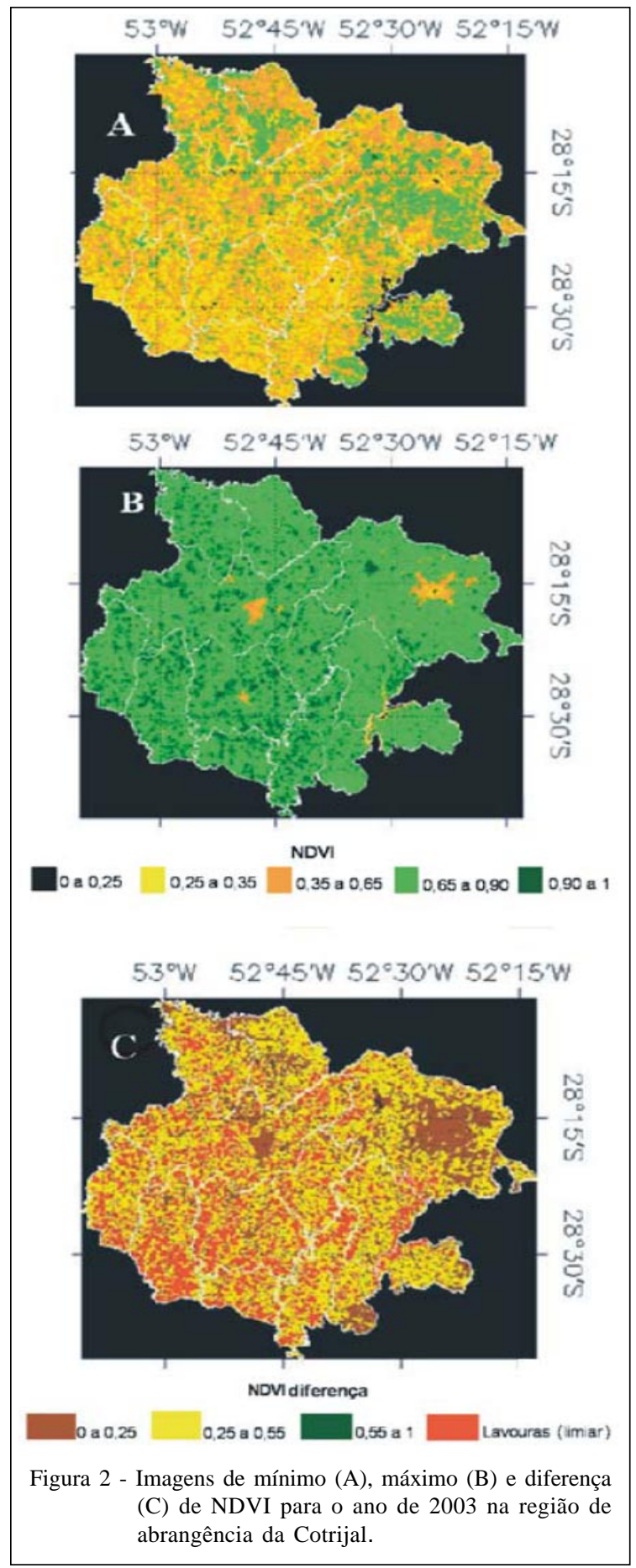

gratuitamente aos usuários, e fácil implementação em rotinas de processamento de imagens.

Salienta-se apenas que, neste trabalho, a geração da máscara de cultivo exigiu a aplicação de limiares distintos para cada um dos anos de estudo. Diferentemente dos trabalhos de FONTANA et al. (2007) com trigo na Austrália e KRELING (2007) com

Ciência Rural, v.39, n.5, ago, 2009. 
Tabela 1 - Área cultivada com cereais de inverno na região de abrangência da Cotrijal (IBGE) e área estimada por meio da metodologia máscara de cultivo para o período de 2000 a 2006.

\begin{tabular}{|c|c|c|c|c|c|c|c|}
\hline \multirow{2}{*}{ Ano } & \multicolumn{6}{|c|}{-Área Cultivada (ha) - IBGE---------------------------- } & \multirow{2}{*}{ Área Máscara de Cultivo (ha) } \\
\hline & Aveia & Centeio & Cevada & Trigo & Triticale & Total & \\
\hline 2000 & 2.980 & 40 & 30.900 & 31.700 & 0 & 65.620 & 67.035 \\
\hline 2001 & 3.200 & 165 & 25.280 & 39.134 & 0 & 67.779 & 71.114 \\
\hline 2002 & 2.550 & 0 & 24.110 & 46.750 & 0 & 73.410 & 77.420 \\
\hline 2003 & 2.500 & 0 & 14.150 & 67.350 & 0 & 84.000 & 84.880 \\
\hline 2004 & 2.100 & 100 & 22.062 & 62.250 & 0 & 86.512 & 95.112 \\
\hline 2005 & 2.200 & 130 & 22.500 & 47.480 & 0 & 72.310 & 76.638 \\
\hline 2006 & 2.480 & 150 & 12.260 & 28.005 & 80 & 42.975 & 45.562 \\
\hline
\end{tabular}

arroz no Rio Grande do Sul, não foi encontrado um valor de limiar único para todos os anos. Este fato indica a necessidade de aprofundamento no estudo da geração de máscaras de culturas para cereais de inverno no Rio Grande do Sul.
Os perfis temporais de NDVI, obtidos com e sem a aplicação da máscara de cultivo (NDVI regional e NDVI máscara de cultivo, respectivamente), para os anos de 2000 a 2006, podem ser visualizados na figura 3. Os perfis temporais de NDVI regional apresentaram,

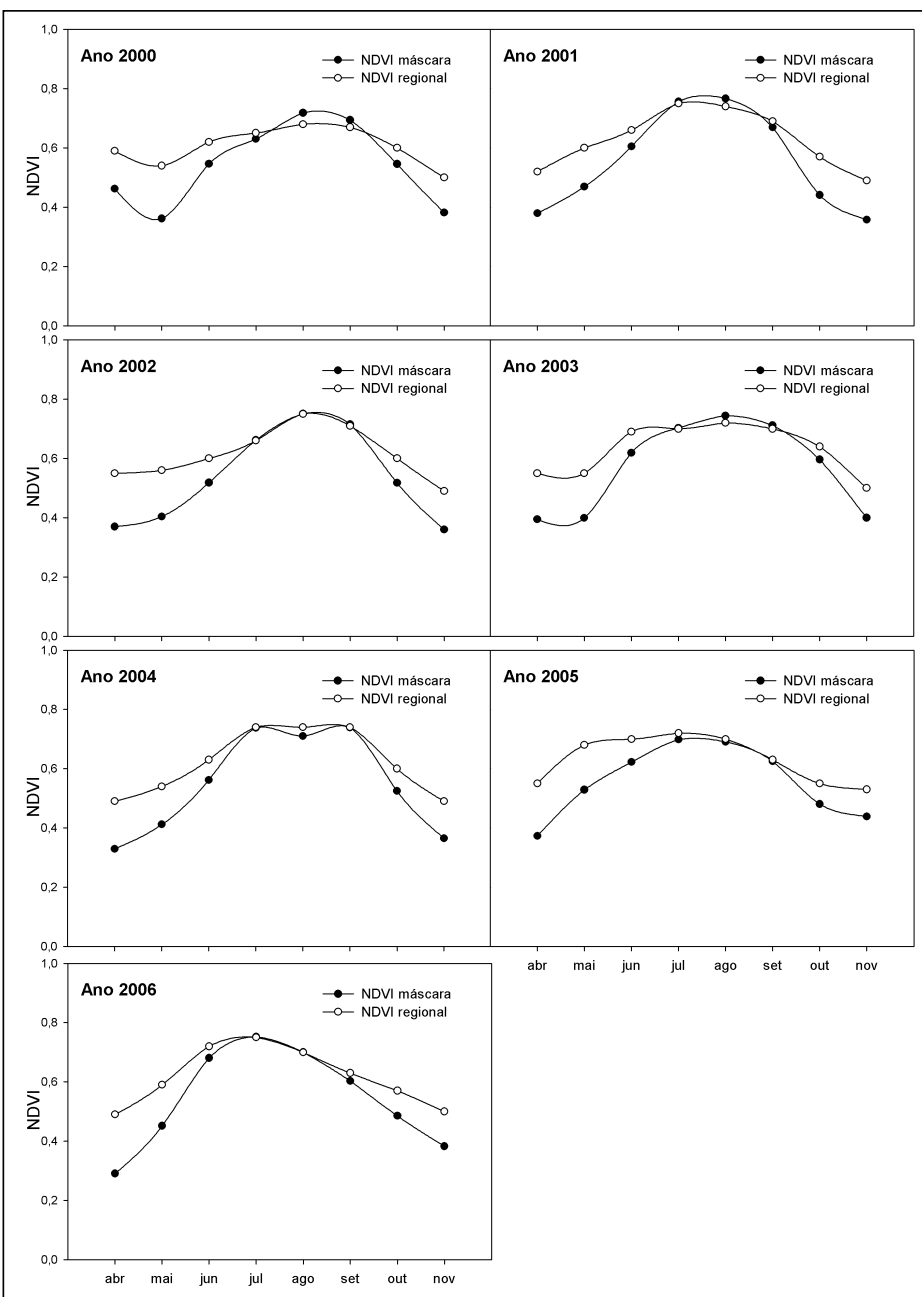

Figura 3 - Perfis temporais de NDVI regional e máscara de cultivo para os anos 2000 a 2006 na região de abrangência da Cotrijal.

Ciência Rural, v.39, n.5, ago, 2009. 
em geral, valores superiores aos observados nos perfis temporais referentes à máscara de cultivo, especialmente no início e final do ciclo. Tal resultado já era esperado em função de estarem incluídas, nos perfis de NDVI regional, informações referentes não somente às lavouras, mas também às matas, aos corpos d’água e às áreas urbanas. O emprego da máscara de cultivo, por sua vez, gerou perfis de NDVI muito semelhantes aos perfis das lavouras de cereais de inverno apresentados na figura 1 , ou seja, perfis que salientam o comportamento espectral de lavouras. A evolução temporal do NDVI observada neste estudo corrobora o trabalho de EPIPHANIO et al. (1996) para a cultura do trigo. Sendo assim, infere-se, novamente, que a metodologia de extração dos dados espectrais, via geração da máscara de cultivo, foi válida ao permitir que somente informações referentes a áreas de lavouras fossem empregadas nos perfis temporais de NDVI. Também DEPPE et al. (2007) verificaram que imagens diferença, obtidas a partir de imagens NDVI/ MODIS, mostraram-se adequadas ao monitoramento do desenvolvimento dos cereais de inverno (trigo e aveia) e a estimativas de áreas no Paraná.

Os perfis temporais de NDVI máscara de cultivo apresentaram variações interanuais que podem estar associadas a variações da produção de biomassa e rendimento de grãos. Para melhor compreensão e caracterização dos perfis temporais de NDVI máscara de cultivo, estes foram apresentados separadamente: anos com rendimento de grãos inferior e superior a $1.800 \mathrm{~kg} \mathrm{ha}^{-1}$ (Figura 4). Em anos nos quais os valores

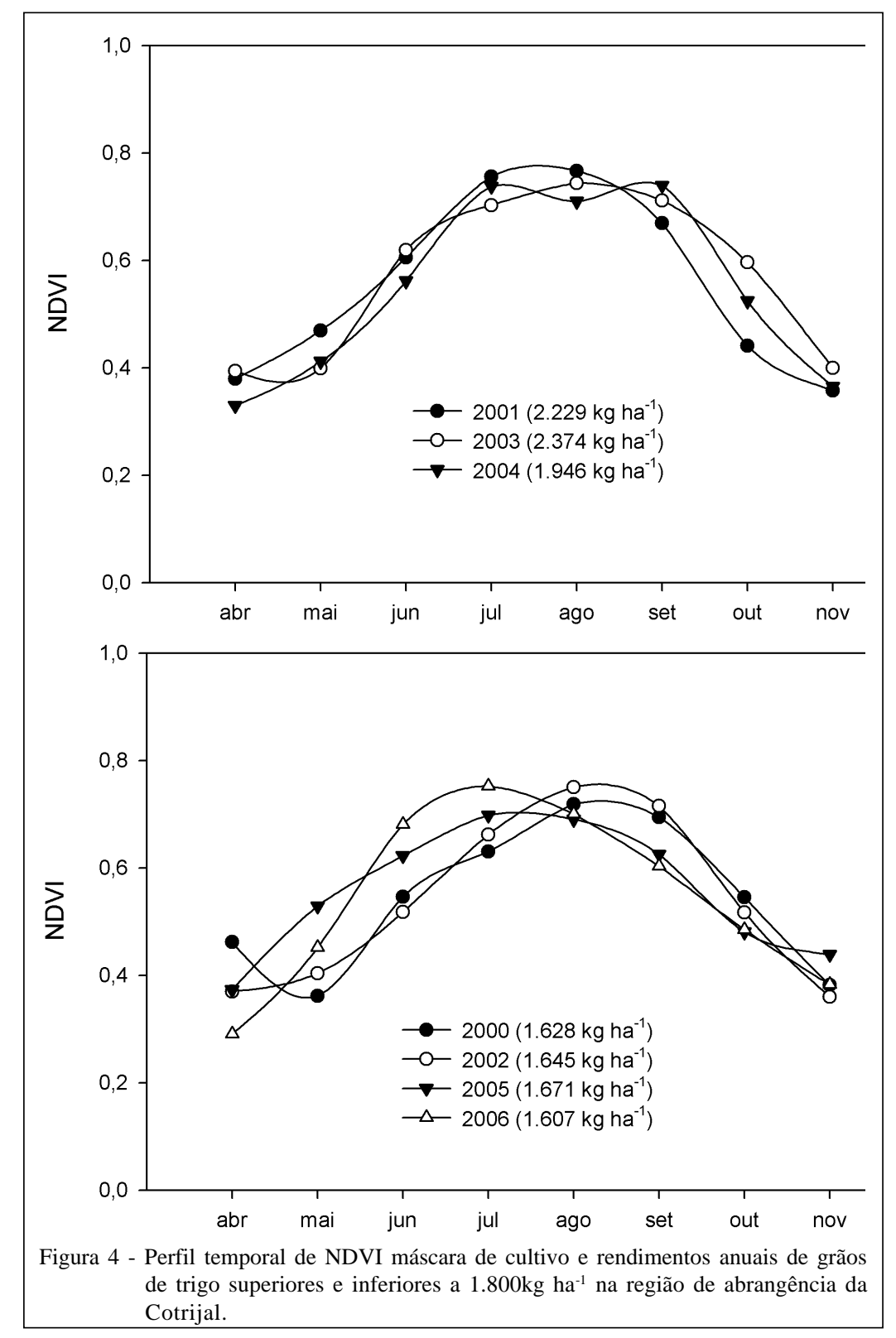

Ciência Rural, v.39, n.5, ago, 2009. 
foram inferiores a $1.800 \mathrm{~kg} \mathrm{ha}^{-1}$, os perfis indicaram rápido aumento ou decréscimo no NDVI ou, como no caso de 2005, o valor não foi superior a 0,7 , indicando menor acúmulo de biomassa. Por sua vez, anos de maiores rendimentos de grãos possuem perfis em que altos valores de NDVI foram mantidos por um período maior (maior área sob a curva), o que corrobora o resultado obtido por RUDDORF \& BATISTA (1990). Para trigo, a manutenção do NDVI parece estar mais associada ao rendimento de grãos do que ao valor do índice propriamente dito. Neste trabalho, o NDVI integrado de junho a outubro apresentou coeficiente de correlação de 0,83 com o rendimento de grãos.

\section{CONCLUSÕES}

Máscaras de cultivo, geradas a partir de imagens MODIS, permitem a obtenção de perfis temporais de NDVI que caracterizam adequadamente o desenvolvimento das lavouras de cereais de inverno em uma análise regional no Estado do Rio Grande do Sul. Da mesma maneira, por apresentarem variações interanuais associadas à variação de rendimento de grãos, os perfis temporais de NDVI fornecem informações que podem ser empregadas em programas de monitoramento e previsão de safra.

\section{REFERÊNCIAS}

DEPPE, F. et al. Monitoramento da evolução temporal de cultivos agrícolas através de imagens TERRA/MODIS. In: SIMPÓSIO BRASILEIRO DE SENSORIAMENTO REMOTO, 13., 2007, Florianópolis. Anais... São José dos Campos: INPE, 2007. p.145-152. Disponível em: <http://marte.dpi.inpe.br/ col/dpi.inpe.br/sbsr@80/2006/11.14.19.13/doc/145-152.pdf >. Acesso em: 28 nov. 2008.

EPIPHANIO, J.C.N. et al. Desenvolvimento do trigo avaliado com dois Índices de Vegetação. In: SIMPÓSIO BRASILEIRO DE SENSORIAMENTO REMOTO, 8., 1996, Salvador, BA. Anais... São José dos Campos: INPE, 2001. p.19-24. Disponível em: < http://marte.dpi.inpe.br/col/sid.inpe.br/deise/ 1999/02.01.11.34/doc/T158.pdf >. Acesso em: 05 dez. 2008.
FONTANA, D.C. et al. Assessing the relationship between shire winter crop yield and seasonal variability of the MODIS NDVI and EVI images. Applied GIS, Victoria, v.3, n.1, p.116, 2007.

HAMADA, E. Desenvolvimento fenológico do trigo (cultivar IAC 24 - Tucuruí), comportamento espectral e utilização de imagens NOAA-AVHRR. 2000. 175f. Tese (Doutorado em Engenharia Agrícola) - Universidade Estadual de Campinas.

IBGE. Levantamento sistemático da produção agrícola. Disponível em:www.ibge.gov.br. Acesso em: 28 nov. 2008.

KLERING, E.V. Avaliação do uso de imagens MODIS na modelagem agrometeorológica-espectral de rendimento do arroz irrigado no Rio Grande do Sul. 2007. $116 f$. Dissertação (Mestrado em Sensoriamento Remoto) - Programa de Pós-graduação em Sensoriamento Remoto, Universidade Federal do Rio Grande do Sul.

MOREIRA, M.A. et al. Variação espectral e eficiência de uso da radiação fotossinteticamente ativa em ensaio com genótipos de trigo. Bragantia, Campinas, v.64, n.3 p.331338, 2005. Disponível em: <http://www.scielo.br/ scielo.php ? script $=$ sci_art text \& pid $=$ S 0006 $87052005000300003 \& \operatorname{lng}=$ en $\& n r m=i s o \& t \operatorname{lng}=p t>$. Doi: 10.1590/S0006-87052005000300003.

RAFAELLI, D.R. et al. Imagens TERRA/MODIS para verificação do impacto de geadas na região cafeeira de Cornélio Procópio, Paraná. Energia na Agricultura, Botucatu, v.21, n.2, p.33-44, 2006. Disponível em: <http://www.fca.unesp.br/ CD_REVISTA_ENERGIA_vol6/vol21n22006/artigos/ Debora\%20Rosa\%20Rafaelli.pdf >. Acesso em: 11 dez. 2008.

REUNIÃO DA COMISSÃO SUL-BRASILEIRA DE PESQUISA DE TRIGO E TRITICALE, 38., 2006, Passo Fundo. Informações Técnicas para a safra 2007: trigo e triticale. Passo Fundo: Embrapa Trigo, 2006. 114p.

RUDORFF, B.F.T, BATISTA, G.T. Spectral response of wheat and its relationship with agronomic variables in the tropical region. Remote Sensing of Environment, EUA, v.31, p.5363, 1990. Disponível em: <http://www.sciencedirect.com/ science?_ob=ArticleURL\&_udi=B6V6V-488NP80S\&_user $=687358 \& \_r d o c=1 \& \_f m t=8 \_$orig $=$search\&_sort $=$ d \& view = c \&_acct $=$ C $000037899 \&$ _version $=$ $1 \&$ u r l V e r s i o $n=0 \&$ u s e r i d $=687$ 358\&md5=a562ab7b6558bbc2f760b67478184386>. Doi: 10.1016/0034-4257(90)90076-X. 